\title{
TRANSIENT ANALYSIS OF HEAT TRANSFER ACROSS THE RESIDENTIAL BUILDING ROOF WITH PCM AND WOOD WOOL- A CASE STUDY BY NUMERICAL SIMULATION APPROACH
}

\author{
D. PRAKASH ${ }^{1}$, P. RAVIKUMAR ${ }^{2}$
}

\begin{abstract}
In this paper, transient analysis on heat transfer across the residential building roof having various materials like wood wool, phase change material and weathering tile is performed by numerical simulation technique. 2-dimensional roof model is created, checked for grid independency and validated with the experimental results. Three different roof structures are included in this study namely roof with (i). Concrete and weathering tile, (ii). Concrete, phase change material and weathering tile and (iii). Concrete, phase change material, wood wool and weathering tile. Roof type 3 restricts $13 \%$ of heat entering the room in comparison with roof having only concrete and weathering tile. Also the effect of various roof layers' thickness in the roof type 3 is investigated and identified that the wood wool plays the major role in arresting the entry of heat in to the room. The average reduction of heat is about $10 \%$ for an increase of a unit thickness of wood wool layer.
\end{abstract}

Keywords: Heat transfer, Residential building roof, Phase change material, Wood wool, Numerical simulation

\section{INTRODUCTION}

Nowadays people spent majority of their times inside the building and facing many health related symptoms due to high indoor temperature especially for the buildings without air conditioning system. This symptom rate will be higher for the occupants living in the hot region. However, the high symptom rate is mainly due to enormous amount of heat transferring through the roof structure. VIJAYAKUMAR et al [1] stated that the heat transmission across the building roof is about $50-70 \%$ of the total heat entry for the room below the exposed roof. CHOU et al [2] also stated that heat gain through the roof due to solar radiation incident on the roof reaches to more than $1000 \mathrm{~W} / \mathrm{m}^{2}$ in clear sky condition and this radiation may be absorbed by 20 to $95 \%$.

In this contest, many research works has been made to reduce the heat transmission across the roof that includes the roof with phase change material, reflective coating, green roofs and etc. Several promising developments were made in the application of PCM for heating and cooling of buildings. Pasupathy and VeLRAJ [3] studied the effect

1 Mechanical Engineering Department, Anna University, Chennai, India.

Email: dee_prakas@yahoo.com, (Corresponding author).

2 Mechanical Engineering Department, Mahendra engineering college, Mahendhirapuri, India 
of double layer phase change material in building roof, increases the thermal storage capacity of the building and enhances the human comfort by decreasing the frequency of internal air temperature swing. Alqallf and Alawdin [4] made a thermal analysis on a building concrete roof with cylindrical holes filled with PCM and reduce the heat flux at the indoor surface of the roof in the range of $9 \%$ to $17 \%$. Also for the conical holes, the heat flux is reduced up to $39 \%$ (Alqallf and Alawdin [5]). Similarly, the roof with green vegetation is also playing a good role in reducing the heat gain. OLIVIERI et al [6] analyzed the thermal energy behavior of a green roof during the summer and stated that the incoming thermal gain is about $60 \%$ lower than for the roof having no vegetation. DVORAK and Volder [7] investigated the under surface and membrane level temperature of an un irrigated green roof and found that the un irrigated succulent based green roof can provide significant roof top temperature reduction during hot dry summer condition. Also the grassed roof produces a significant cooling effect through evaporative cooling when compared to different colored paint surfaces (TAKEBAYASHI [8]). Even though, some advanced cool colored materials have been available along with NIR reflective pigments to cool the roof. Synnefa et al [9] estimated the effect of cool coating on thermal comfort and stated that increasing the roof solar reflectance reduces the cooling load by $18-93 \%$ and the indoor thermal comfort is improved by decreasing the hour of discomfort by $9-100 \%$. HARRY SuEHRCKE et al [10] has stated that light color coating may help to reduce $30 \%$ total heat gain in the weather condition of Australia since the roofing may have much lower absorptivity.

Even though the above methods are more suitable in reducing the heat gain to the room, the cost incurred for the making such a roof should be considered. The initial cost associated for making the green roof is higher and it is difficult to maintain properly. It also requires stronger roof beam to support the various roof layers of the green roof. Also in the roof with roof coating, the detoriation of roof coating over the time is a major setback. The settlement of dust over the roof coating may completely spoils the performance of the roof coating (VIJAYAKUMAR et al [1]). With all these information present work proposes and analyzes a new type of roof to reduce the entry of heat gain in to the room with the aid of PCM material along with wood wool through numerical simulation technique. Numerical simulation technique is the most widely used method to simulate the heat transfer across the building (Zhang et al [12] DAvid et al [13]), building indoor thermal comfort (RAVIKUMAR et al $[14,15])$ and also it is the cost effective tool.

\section{RESIDENTIAL BUILDING ROOF- HEAT TRANSFER ANALYSIS}

The heat transfer due to solar radiation across the roof is analyzed by Numerical simulation technique. The 2 dimensional geometry of the roof is modeled in GAMBIT software. For all the analyzed cases the thickness of the concrete layer is taken as $15 \mathrm{~cm}$. Three different types of roof structures are included in this study. In the first 
type, the roof comprises only concrete and weathering tile in which the thickness of the weathering tile is taken as $6 \mathrm{~cm}$. In the second type, the phase change material is added in between the weathering tile and concrete layer for a thickness of $4 \mathrm{~cm}$ by changing the weathering tile layer thickness to $2 \mathrm{~cm}$. In the third type of roof structure, wood wool is included below the weathering tile and all the roof layers except concrete is taken as $2 \mathrm{~cm}$. The schematic representation of the tree types of roof structures included in this study are shown in figure 1.

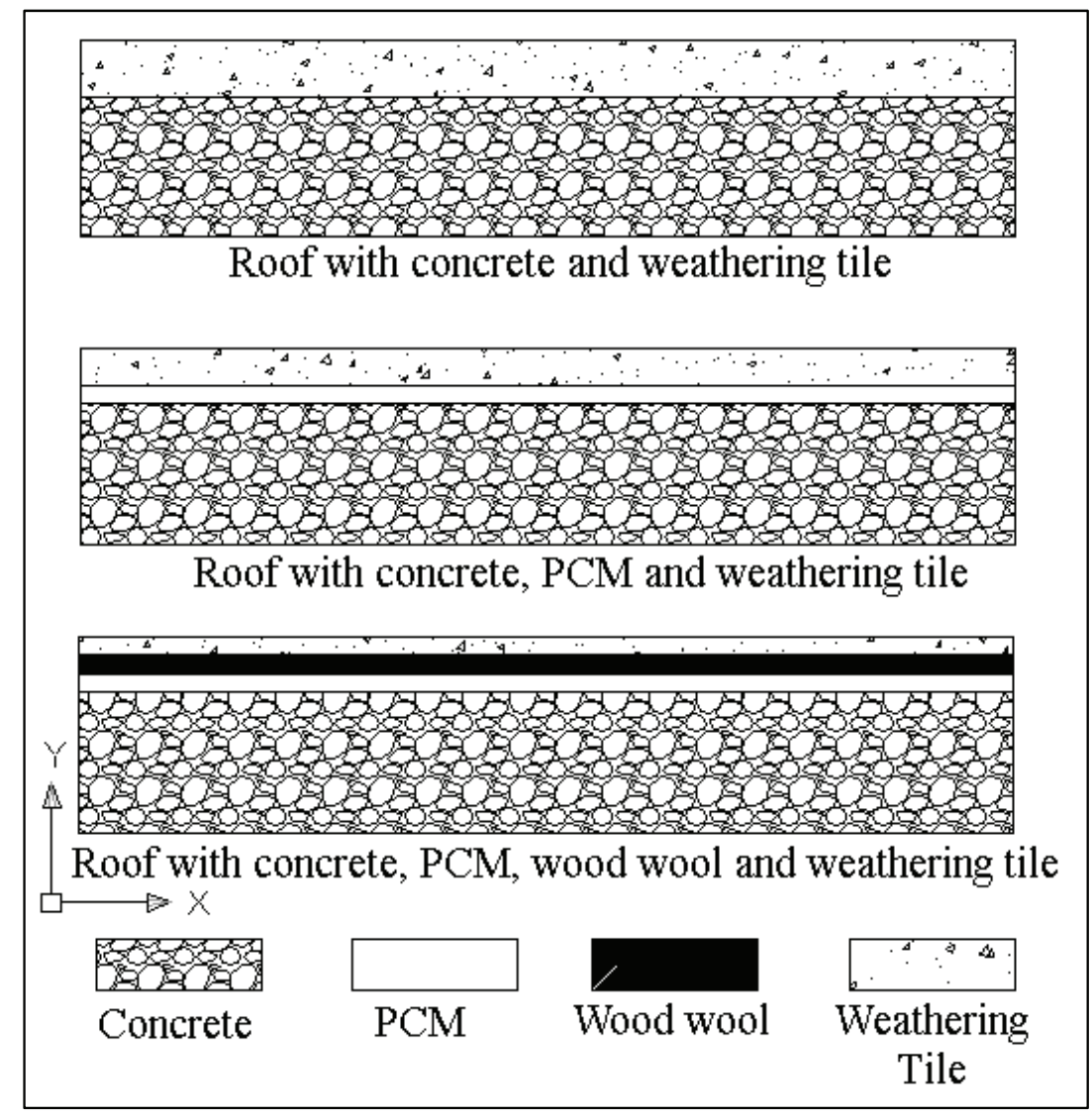

Fig. 1. Schematic representation of residential building roof with various layers

\section{Numerical SimUlation METHODOLOGY}

In the numerical simulation of heat transfer across the roof, the required geometry of the roof structure is modeled in GAMBIT software. The assumptions involved in this numerical simulation of heat transfer across the roof are given below: 
(i) The heat conduction in the composite roof is one dimensional and the end effects are neglected.

(ii) The thermal conductivity of roof materials is considered as constant and not varying with respect to temperature.

(iii) The Phase change material is homogeneous and isotropic.

(iv) The convection effect in the molten PCM is neglected.

(v) The interfacial resistances are negligible.

For the above mentioned assumptions the governing equation for the heat transfer is given in Eq. (3.1).

$$
k_{m} \frac{\partial^{2} T_{m}}{\partial y^{2}}=\rho_{m} c_{p_{m}} \frac{\partial T_{m}}{\partial t} \quad[0<y<L] ; m=1,2,3 \ldots . n
$$

Where, $\mathrm{k}$ is the thermal conductivity of the material, $\mathrm{T}$ is the temperature, density, $\rho$ and $C_{p}$ is the specific heat.

The material properties for various roof constructing materials included in this investigation are given in table 1 .

Table 1

Material properties of the roof constructing materials

\begin{tabular}{|c|c|c|c|}
\hline Roof material & $\begin{array}{c}\text { Density } \\
\mathrm{Kg} / \mathrm{m}^{3}\end{array}$ & $\begin{array}{c}\text { Thermal conductivity } \\
\mathrm{W} / \mathrm{m} . \mathrm{K}\end{array}$ & $\begin{array}{c}\text { Specific heat } \\
\mathrm{J} / \mathrm{Kg} . \mathrm{K}\end{array}$ \\
\hline Concrete & 2300 & 1.279 & 1130 \\
\hline Weathering tile & 1300 & 0.25 & 1300 \\
\hline Wood wool & 500 & 0.1 & 1000 \\
\hline $\begin{array}{c}\text { Phase change } \\
\text { material }\end{array}$ & 1640 & $\begin{array}{c}1.09\left(0-27^{\circ} \mathrm{C}\right) ; 0.54\left(28-60^{\circ} \mathrm{C}\right) \\
\text { (Pasupathy et al }[11])\end{array}$ & $\begin{array}{c}1440\left(0-26.5^{\circ} \mathrm{C}\right) ; 125,000 \\
(\text { Pasupathy et al }[11])\end{array}$ \\
$($ Pasupathy et al $[11])$
\end{tabular}

\subsection{BOUNDARY CONDITIONS AND SOLUTION METHODOLOGY}

Roof Top: Solar radiation data for the month of May at Chennai are specified at the roof top. This solar radiation value is converted into $T_{\text {solair }}$ through the Eq. (3.2). The variation of solar radiation and the calculated $\mathrm{T}_{\text {solair }}$ for the month of May at Chennai is shown in figure 2 .

$$
T_{\text {solair }}=T_{a}+\left(\alpha q / h_{o}\right)
$$


Where $T_{a}$ is the ambient temperature, $\alpha$, absorvity, $q$, solar radiation and $h_{o}$ convective heat transfer coefficient at the outer surface.

Roof bottom surface: Temperature is assumed constant as $298 \mathrm{~K}$ with a convective heat transfer coefficient of $10 \mathrm{~W} / \mathrm{m}^{2} \mathrm{~K}$.

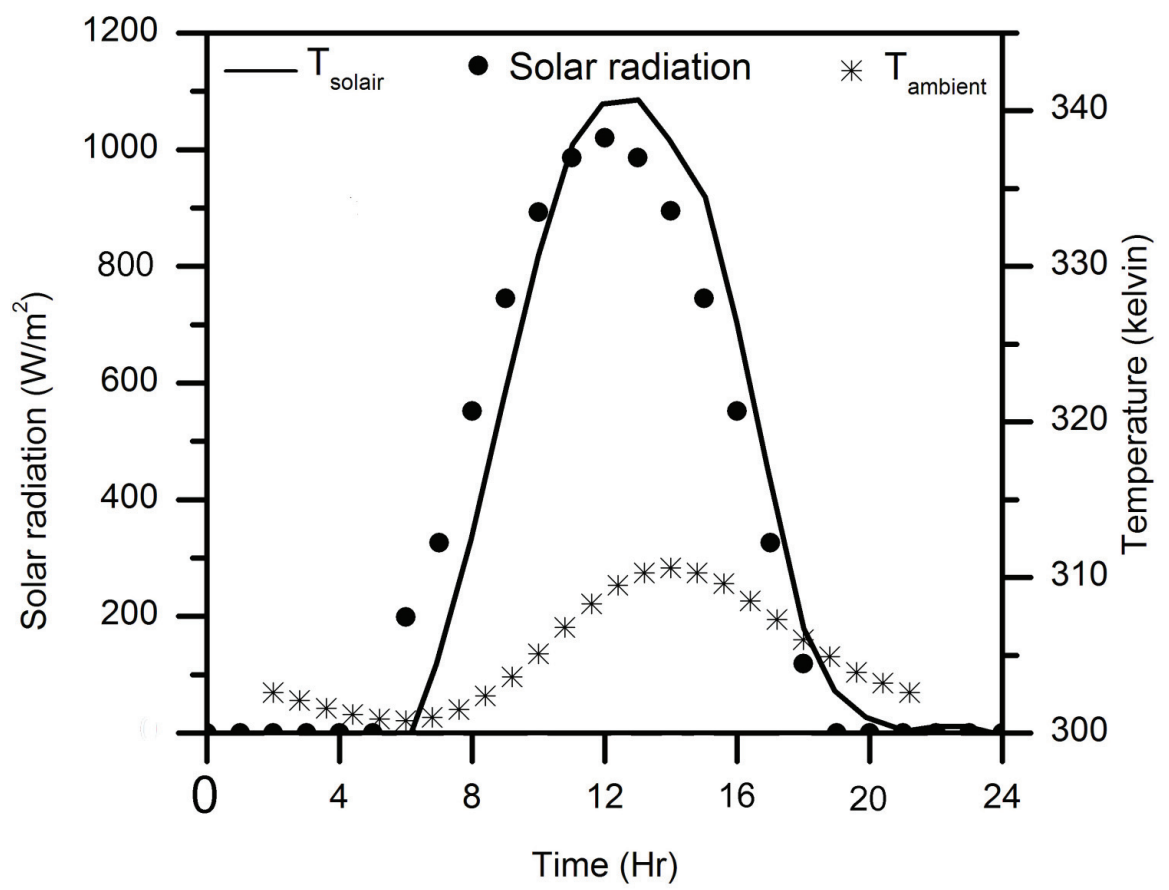

Fig. 2. Solar radiation and the calculated $\mathrm{T}_{\text {solair }}$ temperature data for the month of May at Chennai

The roof domain is initially analyzed under steady state with double precision segregated solver. Later it is solved under transient state for one complete cycle of $24 \mathrm{hrs}$ with second order implicit method. To avoid the effect of initial condition on the result, the solution has been marched in time repeatedly over the days till the temperature distribution at the end of the two consecutive days will be same. All the cases are iterated up to the convergence level of $10^{-6}$. The above numerical simulation is validated with the experimental predictions made by Pasupathy et al [11]. In this validation, the same roof model made by PASUPATHY et al [11] is modeled in GAMBIT software and the same boundary conditions are applied. The numerically simulated temperature at the bottom of the roof surface is compared with the experimental predictions (Pasupathy et al [11]) and is shown in figure 3. This figure 3 infers that the numerical simulation of thermal behavior across the roof is having a good agreement with experimental results. 


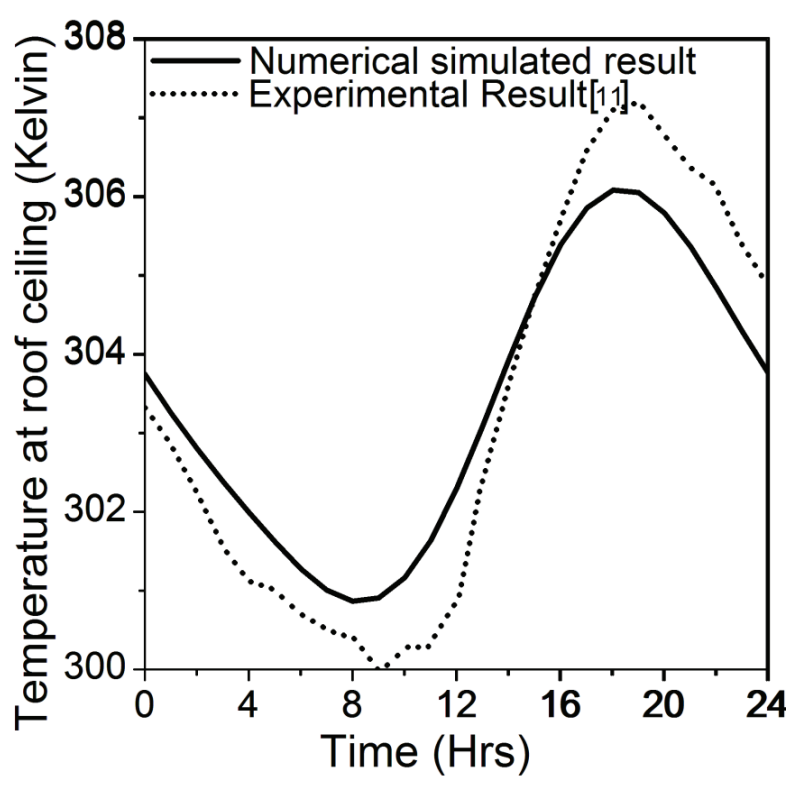

Fig. 3. Validation of Numerical simulation of heat transfer across Roof with Experimental results (Pasupathy et al [11])

\section{Thermal BEHAVIOR OF ROOF STRUCTURES}

The thermal behavior for the three types of roof structures are analyzed for one complete 24 hours and their corresponding temperature plots at the time of $14 \mathrm{hr}$ is shown in figure 4 . At time $=14 \mathrm{hr}$, the average temperature at the bottom of the roof is predicted as $301.32 \mathrm{~K}, 301.9 \mathrm{~K}$ and $300.8 \mathrm{~K}$ for the three roof structures respectively. This shows that the second type structure stores enormous amount of heat that causes the ceiling temperature to get increase in comparison with the first type. Hence additional layer wood wool is provided below the weathering tile that reduces the ceiling temperature to a value of $300.8 \mathrm{~K}$. Also it is well identified that for the roof type 3 , the temperature below the wood wool layer is comparatively lower than the rest of the roof structures.

In the figure 5, the variation of temperature across the roof is plotted for the time $6,10,12,14,18$ and $24 \mathrm{hrs}$. At the time of $10 \mathrm{hr}$, the temperature lowers drastically and linearly from $y=0.21$ to $0.15 \mathrm{~m}$ for the roof type 1 . The weathering tile reduces the temperature from $325 \mathrm{~K}$ to $305 \mathrm{~K}$. For the roof type 2 , the temperature is reduced from $322 \mathrm{~K}$ to $312 \mathrm{~K}$ by weathering tile and PCM layer reduces the temperature from $312 \mathrm{~K}$ to $305 \mathrm{~K}$. For the roof type 3 , weathering tile reduces the temperature from $325 \mathrm{~K}$ to $320 \mathrm{~K}$, wood wool reduces from 320 to $305 \mathrm{~K}$ and PCM reduces the temperature from $305 \mathrm{~K}$ to $303 \mathrm{~K}$. By using the wood wool layer, the top face of the PCM layer is exposed 


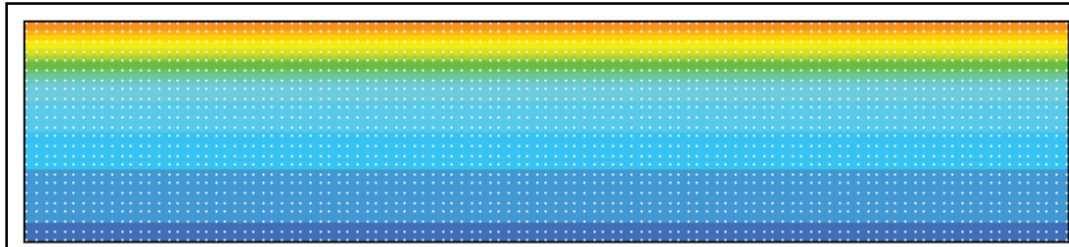

Roof with concrete and Weathering tile

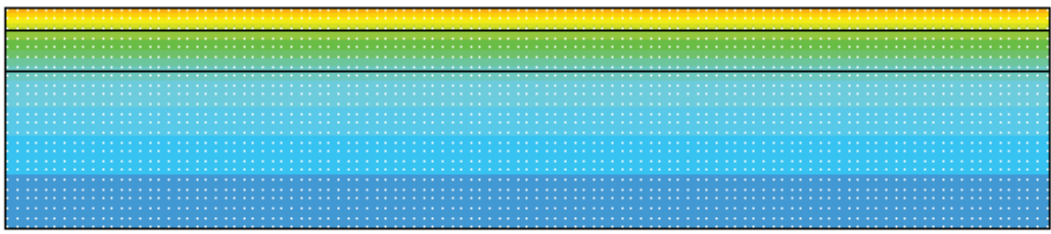

Roof with concrete, PCM and Weathering tile

Roof with Concrete, Wood wool, PCM and Weathering tile

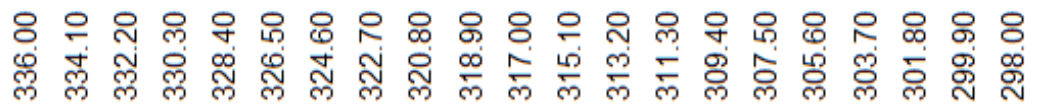

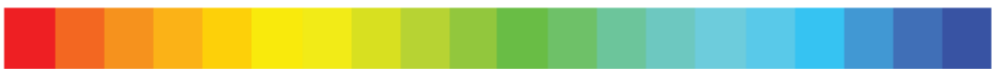

Fig. 4. Temperature plots across the roof at time $=14 \mathrm{hr}$

to a temperature of $305 \mathrm{~K}$ where as the roof without wood wool causes the top face of the PCM to expose with a temperature of $312 \mathrm{~K}$. This $7^{\circ} \mathrm{C}$ variation causes the PCM to accumulate more amount of heat energy.

At time of 12 and $14 \mathrm{hr}$, the temperature variation follows a similar trend. In the roof type 1 , the weathering tile reduces the temperature from $332 \mathrm{~K}$ to $310 \mathrm{~K}$. However, in roof type 2 , the weathering tile reduces the temperature from $328 \mathrm{~K}$ to $320 \mathrm{~K}$ and PCM layer reduces the temperature from $320 \mathrm{~K}$ to $310 \mathrm{~K}$. For the roof type 3 , the weathering tile reduces the temperature from $335 \mathrm{~K}$ to $327 \mathrm{~K}$, wood wool reduces the temperature to $310 \mathrm{~K}$ and the PCM layer further reduces the temperature to $305 \mathrm{~K}$. For the time of $18 \mathrm{hr}$, the temperature gradually reduces from $\mathrm{Y}=0.21 \mathrm{~m}$ to $0 \mathrm{~m}$ for the roof type 1 and 2 , whereas for the roof type 3, the reduction in temperature is identified as 
piecewise linear. The temperature along the weathering tile is almost constant, followed by a drastic reduction across the wood wool and gradually falls along the PCM and concrete. However for the time of 6 and $24 \mathrm{hr}$ the variation in temperature across the roof is not appreciable and almost constant about $302 \mathrm{~K}$. From this figure it is very clear that the roof with PCM layer along with weathering tile increases the ceiling temperature and hence an insulator like wood wool is required to reduce the ceiling temperature.

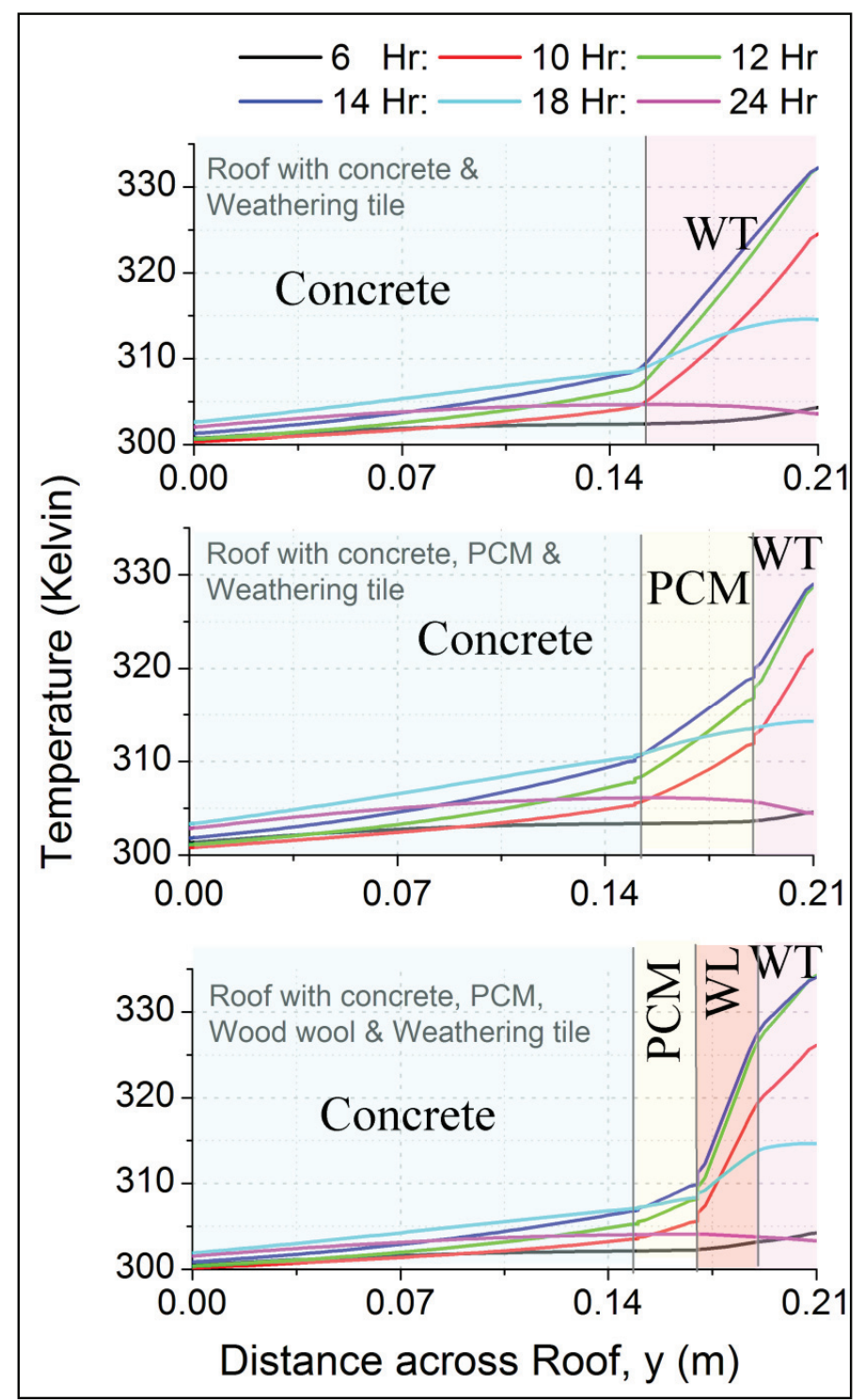

Fig. 5. Variation of temperature across the roof at time $=6,10,12,14,18 \& 24 \mathrm{hr}$ 
The figure 6 shows the variation in temperature and heat at the roof bottom (Ceiling) for the three types of roof structure for one complete $24 \mathrm{hrs}$.

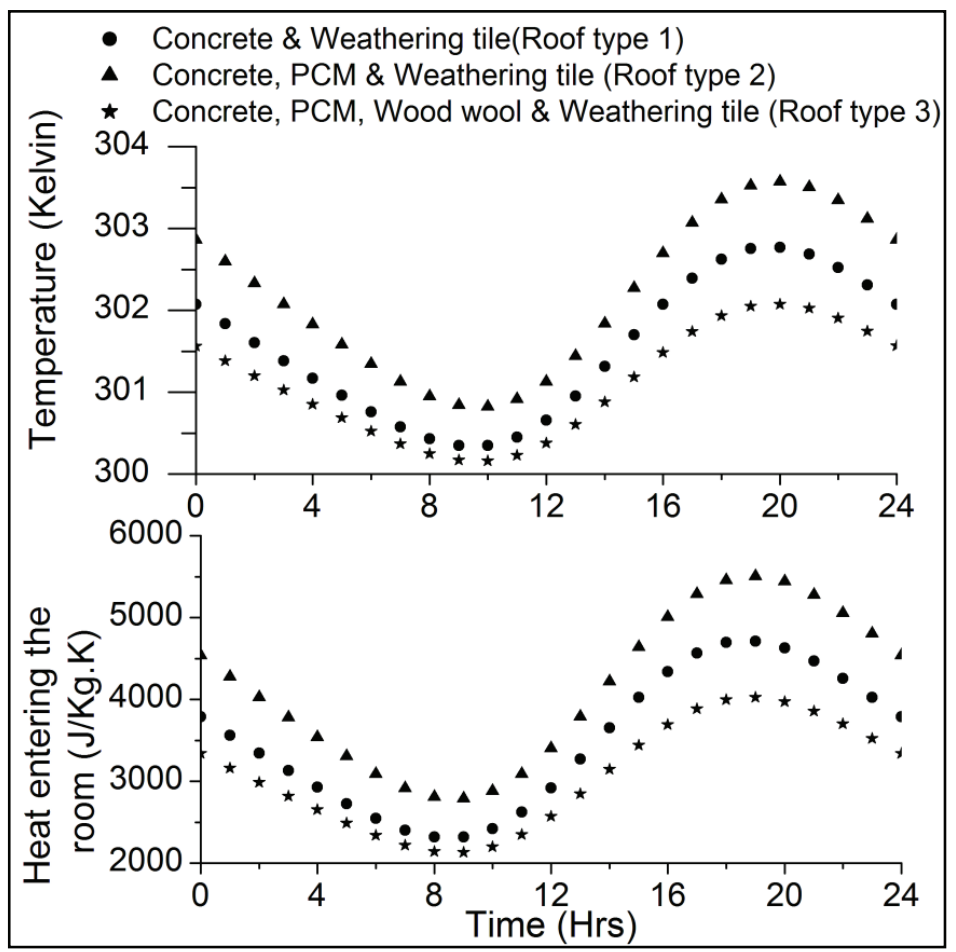

Fig. 6. Variation of temperature and heat at the roof bottom for one complete $24 \mathrm{hrs}$

The temperature and heat at the roof ceiling decreases gradually from time $=0 \mathrm{hr}$ to $10 \mathrm{hr}$ and rises gradually up to time $=20 \mathrm{hr}$ and again falls down to the time of $24 \mathrm{hr}$ for all the type of roof structure. This figure clearly depicts that roof with PCM and weathering tile (roof type 2) shows comparatively high temperature at the ceiling for complete 24 hrs, whereas the roof with PCM, wood wool and weathering tile (type 3) reduces the average ceiling temperature by $1^{\circ} \mathrm{C}$. Also for the roof type 3 , the variation of temperature for one complete $24 \mathrm{hrs}$ is noticed as $1.8^{\circ} \mathrm{C}$, whereas for the roof type 2 it is $3^{\circ} \mathrm{C}$. Similarly, the roof type 3 reduces the average heat that entering the room through the roof ceiling by $1300 \mathrm{~J} / \mathrm{Kg} . \mathrm{K}$ in comparison with roof type 2 .

In general, roof with PCM material absorbs more amount of heat energy during the day time and this heat energy is released during the night time to make uniform interior condition. However adding the PCM layer and reducing the thickness of weathering tile increases the heat entering the room and thereby causes a rise in ceiling temperature in comparison with the roof without PCM. Hence additional layer wood wool is laid between the weathering tile and PCM layer that reduces the temperature drastically. 


\section{EFFECT OF ROOF LAYER THICKNESS}

In this section, the effect of increasing the thickness of roof layers such as PCM, wood wool and weathering tile on heat transfer across the roof is performed. The PCM layer thickness is varied as $2 \mathrm{~cm}, 4 \mathrm{~cm}, 6 \mathrm{~cm}$ and $8 \mathrm{~cm}$ by keeping the other roof layers wood wool and weathering tile as constant as $2 \mathrm{~cm}$. Similarly, the wood layer and weathering tile layer are varied by keeping other roof layer as constant. The temperature at the bottom of the roof (ceiling) for one complete $24 \mathrm{hrs}$ is plotted for various thickness of roof layer in the figure 7.

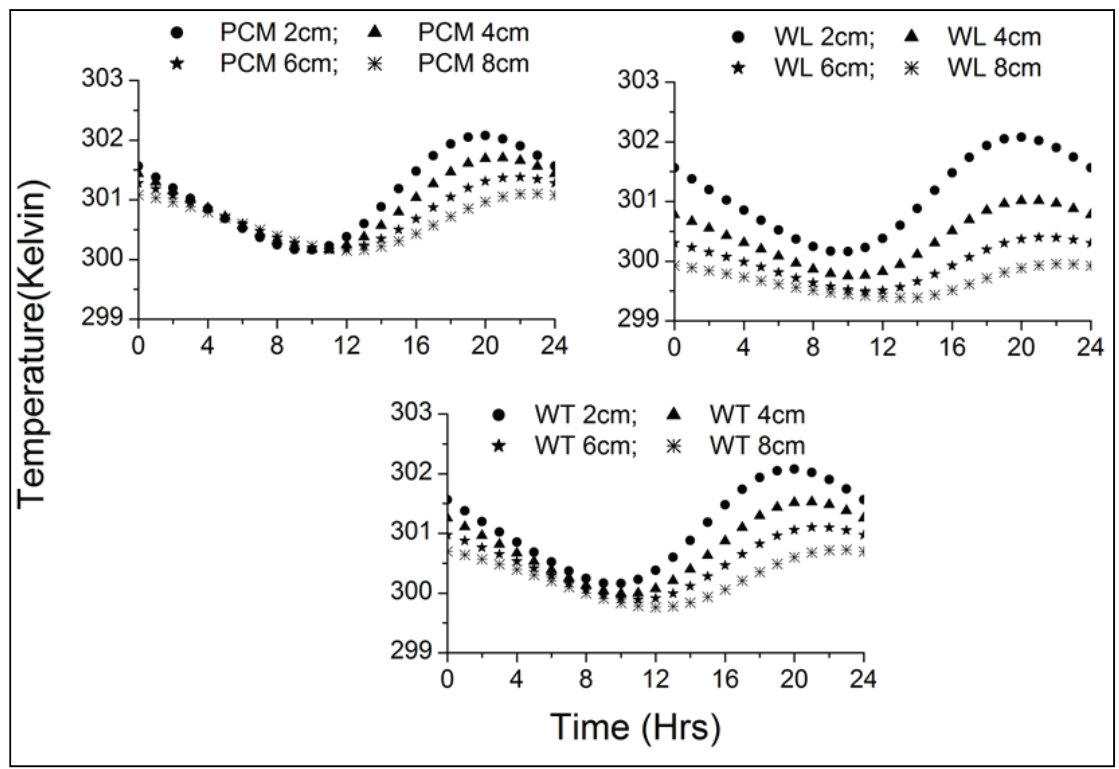

Fig. 7. Variation of ceiling temperature for various roof layer thickness for one complete $24 \mathrm{hrs}$

From this figure, while changing the PCM layer thickness the temperature is not having significant variation from time $=0 \mathrm{hr}$ to $11 \mathrm{hr}$. However from the time of $11 \mathrm{hr}$, the temperature at the roof bottom decreases by increasing the PCM layer thickness. For all the PCM layer thickness, the temperature rises from time $=11 \mathrm{hr}$, attains a maximum value at time $=20 \mathrm{hr}$ and after the time of $20 \mathrm{hr}$ a marginal fall in temperature is noticed. For the PCM layer thickness of $2 \mathrm{~cm}$, the variation in temperature for one complete 24 hours is identified as $2^{\circ} \mathrm{C}$. This variation in temperature is gradually reduced by increasing the PCM layer thickness and finally this temperature variation is noticed as $0.65^{\circ} \mathrm{C}$ for $\mathrm{PCM}=8 \mathrm{~cm}$. In the next study of varying the wood wool layer thickness from $2 \mathrm{~cm}$ to $8 \mathrm{~cm}$ with an increment of $2 \mathrm{~cm}$, the temperature variation is not same during the time between $0 \mathrm{hr}$ to $11 \mathrm{hr}$ as in the previous case. However the variation in temperature for one complete $24 \mathrm{hrs}$ is decreasing by increasing the wood wool layer 
thickness. This variation in temperature is predicted as $1.3^{\circ} \mathrm{c}, 0.9^{\circ} \mathrm{c}$ and $0.55^{\circ} \mathrm{c}$ for the wood wool layer thickness of $4 \mathrm{~cm}, 6 \mathrm{~cm}$ and $8 \mathrm{~cm}$ respectively. For the wood wool layer thickness of $2 \mathrm{~cm}, 4 \mathrm{~cm}, 6 \mathrm{~cm}$ and $8 \mathrm{~cm}$, the temperature gradually decreases from time $=0 \mathrm{hr}$ to $10 \mathrm{hr}, 10.5 \mathrm{hr}, 11 \mathrm{hr}$ and $13 \mathrm{hr}$ respectively. This shows that the wood wool layer of $8 \mathrm{~cm}$ extends the temperature fall during the day time by $3 \mathrm{hrs}$ and also this thickness reduces the average ceiling temperature by $1.6^{\circ} \mathrm{C}$ with reference to the wood wool layer thickness of $2 \mathrm{~cm}$. In the next case of varying the weathering tile thickness, the difference in temperature up to the time of $10 \mathrm{hrs}$ is not significant. Whereas, from the time of $10 \mathrm{hr}$, a drastic reduction in temperature is identified through the rest of the

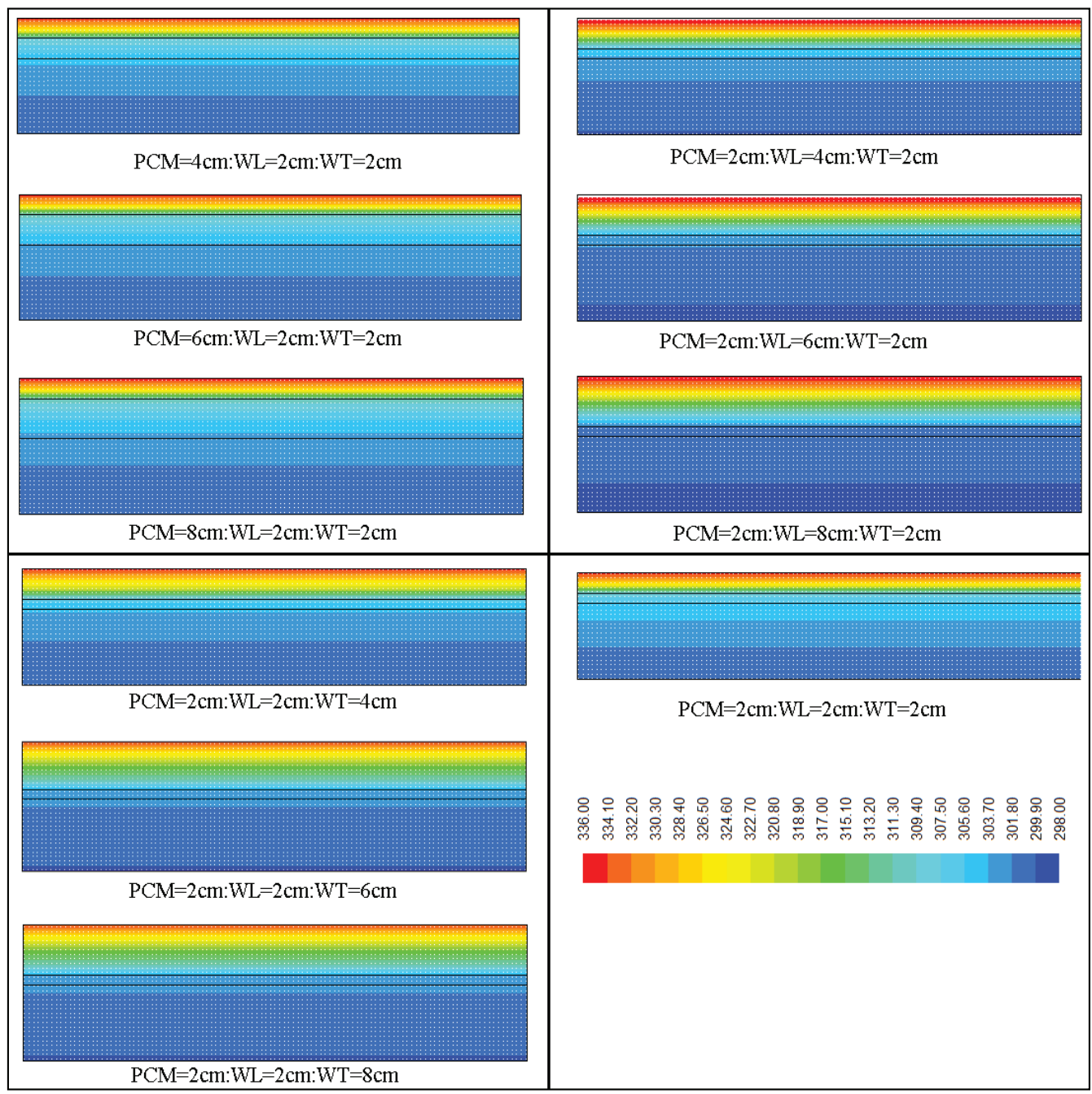

Fig. 8. Temperature plots across the roof various roof layer thickness at time $=14 \mathrm{hr}$ 
time by increasing the weathering tile thickness. Also the temperature variation for one complete $24 \mathrm{hrs}$ for the weathering tile thickness of 2, 4, 6 and $8 \mathrm{~cm}$ are determined as $1.9,1.5,1.2$ and $0.9^{\circ} \mathrm{c}$ respectively. The reduction in the variation of temperature by increasing the weathering tile thickness is not much appreciable in comparison with the change in wood wool layer thickness. This shows that the change in wood wool layer thickness make a drastic effect in reducing the temperature at the bottom of the roof for one complete $24 \mathrm{hrs}$ in comparison with the change in PCM and weathering tile layer thickness.

The temperature plots in the range of $298 \mathrm{~K}$ to $336 \mathrm{~K}$ were plotted across the roof for various thicknesses of roof layers in figure 8 . From this figure it is clearly evident that the roof with higher wood wool layer thickness shows comparatively low temperature at the bottom of the roof. This low temperature region extends to a high distance across the roof for the wood wool layer thickness of $8 \mathrm{~cm}$. Also for the weathering tile case of $6 \mathrm{~cm}$ and $8 \mathrm{~cm}$ a smaller portion nearer to the roof bottom experiences the low temperature.

The heat entering the room through the roof ceiling is shown for various thicknesses of roof layers in figure 9. By varying the PCM thickness the heat at the roof ceiling is similar up to the time $=10 \mathrm{hr}$ from $0 \mathrm{hr}$. However, the ceiling heat for the PCM layer thickness of $8 \mathrm{~cm}$ is higher between the times of $4 \mathrm{hr}$ to $10 \mathrm{hr}$ and lower between the

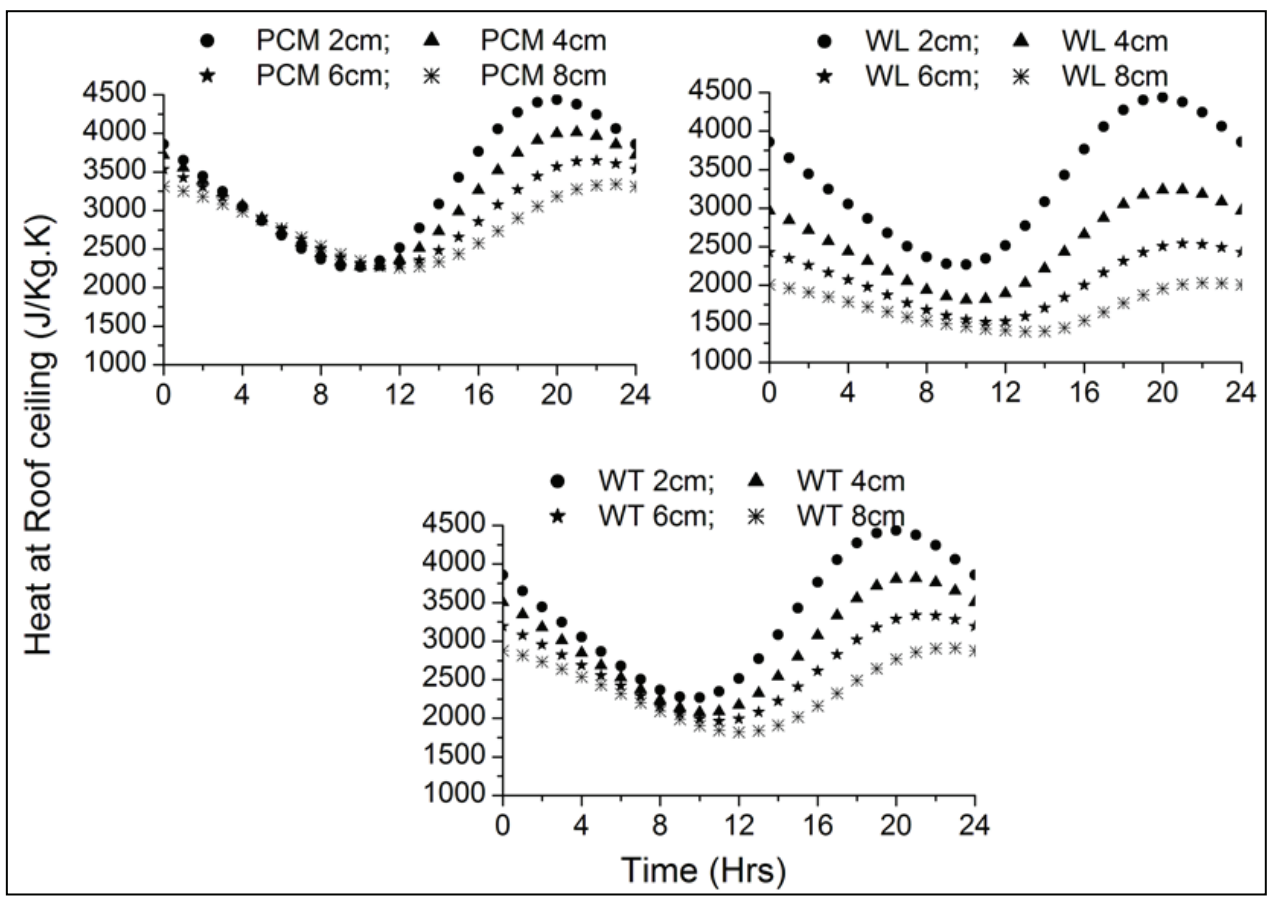

Fig. 9. Variation of Ceiling heat for various roof layer thicknesses for one complete $24 \mathrm{hrs}$ 
times of 0 to $4 \mathrm{hr}$ in comparison with the PCM thickness of $2 \mathrm{~cm}$. Also between the time 12 to $24 \mathrm{hr}$ the variation in ceiling heat is drastically reduced for $\mathrm{PCM}=8 \mathrm{~cm}$ in comparison with other cases.

This shows that by increasing the PCM layer thickness the heat at the ceiling can be maintained at constant value and provides a uniform indoor comfort condition for one complete $24 \mathrm{hrs}$. In the case of varying the thickness wood wool layer, a drastic variation in ceiling heat is noticed for a complete $24 \mathrm{hrs}$. For wood wool of $2 \mathrm{~cm}$ thickness, the ceiling heat reduced from $4000 \mathrm{~J} / \mathrm{Kg} . \mathrm{K}$ to $2500 \mathrm{~J} / \mathrm{Kg} . \mathrm{K}$ between the time $0 \mathrm{hrs}$ to $10 \mathrm{hrs}$ and increases up to $4250 \mathrm{~J} / \mathrm{Kg} . \mathrm{K}$ at time $20 \mathrm{hr}$ and from time $=20 \mathrm{hr}$ a short fall in ceiling heat is noticed. However by increasing the wood wool layer thickness, a drastic reduction in ceiling heat is identified and for the wood wool layer thickness of $8 \mathrm{~cm}$, the heat at the ceiling is almost constant around $2000 \mathrm{~J} / \mathrm{Kg}$.K. By varying the thickness of weathering tile from $2 \mathrm{~cm}$ to $8 \mathrm{~cm}$ the reduction in ceiling heat is smaller between the times 0 to $10 \mathrm{hr}$ in comparison with the time between 12 to 24 $\mathrm{hr}$. This shows that increasing the thickness of weathering tile reduces the ceiling heat effectively between the time 12 to $24 \mathrm{hr}$. From these figures it is well identified that increasing the wood wool layer reduces the ceiling heat drastically in comparison with other roof layers.

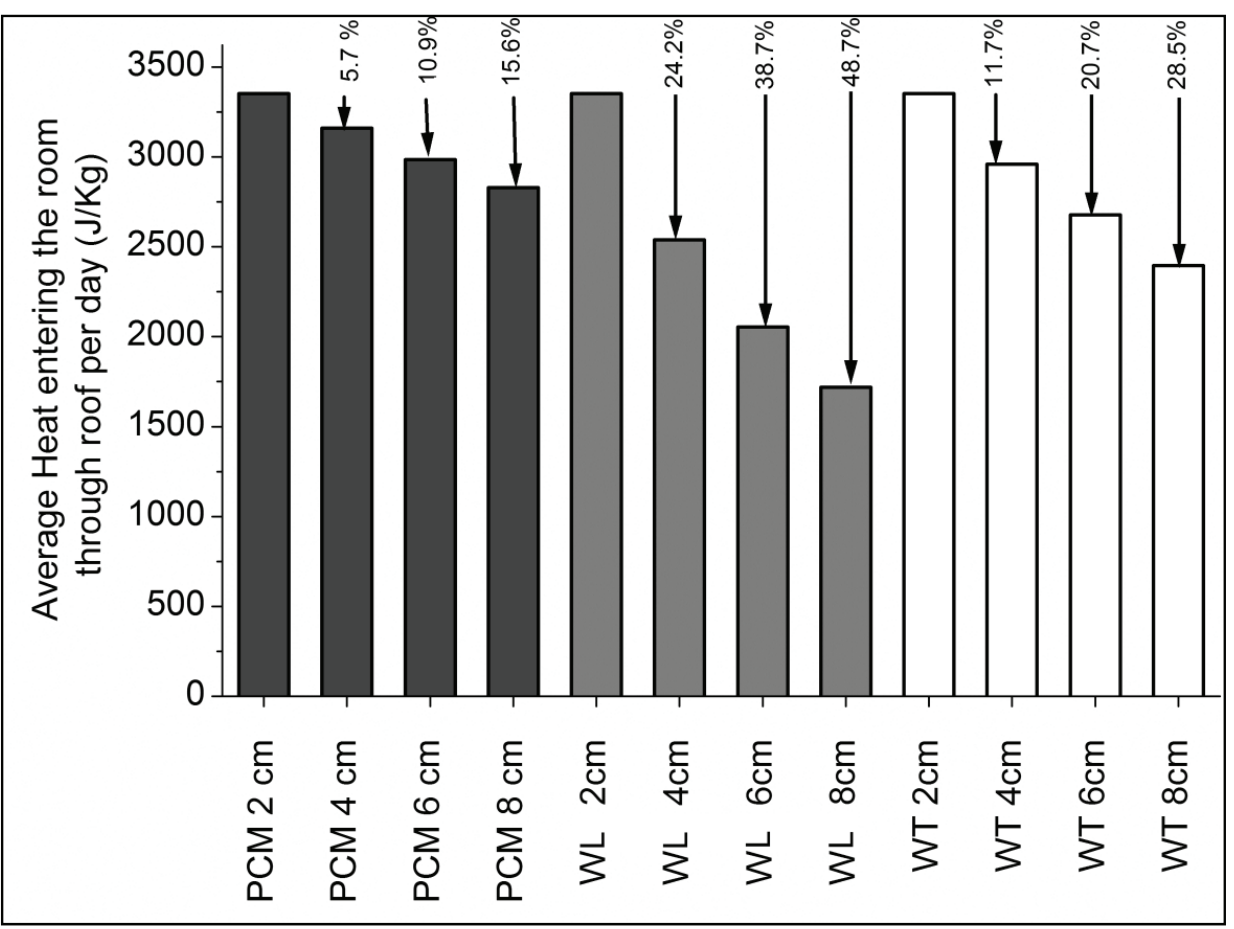

Fig. 10. Average heat entering the room for various roof layer thicknesses 
This is also evident from the figure 10 which shows the average amount of heat entering the room through the ceiling for various roof layer thicknesses.

By increasing the PCM layer thickness as $4 \mathrm{~cm}, 6 \mathrm{~cm}$ and $8 \mathrm{~cm}$ the reduction in heat entering the room is predicted as $5.7 \%, 10.9 \%$ and $15.6 \%$ with reference to the PCM layer thickness of $2 \mathrm{~cm}$. However this reduction in heat entering the room is drastic by increasing the wood wool layer thickness. By changing the wood wool layer thickness of $4 \mathrm{~cm}, 6 \mathrm{~cm}, 8 \mathrm{~cm}$ the average heat entering the room is reduced by $24 \%, 38 \%$ and $48 \%$ with reference to the wood wool layer thickness of $2 \mathrm{~cm}$. Similarly, the weathering tile of thickness $4 \mathrm{~cm}, 6 \mathrm{~cm}$ and $8 \mathrm{~cm}$ reduces heat by $11.7 \%, 20.7 \%$ and $28.5 \%$ with reference to the thickness of $2 \mathrm{~cm}$. It is clearly noticed that a unit increase in the wood wool layer thickness reduces the heat entering the room in a drastic quantity as $10 \%$ where as by increasing the PCM and weathering tile layer thickness the average reduction in heat is 2.8 and $5.3 \%$ respectively per unit thickness.

\section{Conclusion}

In this paper the conventional type of roof with concrete and weathering tile is modified by providing additional material namely phase change material and wood wool to reduce the heat entering the room. The heat transfer across the roof with (i). Concrete and weathering tile, (ii). Concrete, phase change material and weathering tile and (iii). Concrete, phase change material, wood wool and weathering tile are analyzed through numerical simulation technique under transient approach. The numerical simulation method is validated with the experimental result and found that it is having good agreement. The temperature, heat at the bottom of the roof and across the roof is predicted and the thermal behavior for the three types of roofs is discussed. Roof with phase change material, wood wool and weathering tile reduces the average heat that entering the room through the roof ceiling by $500 \mathrm{~J} / \mathrm{Kg} . \mathrm{K}$ and $1300 \mathrm{~J} / \mathrm{Kg} . \mathrm{K}$ in comparison with roof type 1 and 2 respectively. Finally, the effect of increasing the thickness of various roof layers of the roof type 3 is studied. Among the varied roof layers, wood wool plays the major role in arresting the entry of heat in to the room and the average reduction of heat entering the room is about $10 \%$ for an increase of a unit thickness where as by increasing the PCM and weathering tile layer thickness the average reduction of heat is predicted as 2.8 and $5.3 \%$ respectively per unit thickness. 


\section{REFERENCES}

1. K.C.K. Vijaykumar, P.S.S. Srinivasan, S. Dhandapani, A performance of hollow clay tile (HCT) laid reinforced cement concrete (RCC) roof for tropical summer climates ,Energy and Buildings, 39 (2007) 886-892.

2. Huann-Ming Chou, Chang-Ren Chen, Vu-Lan Nguyen, A new design of metal-sheet cool roof using PCM, Energy and Buildings, 57, 42-50, 2013.

3. A. Pasupathy, R. Velraj, Effect of double layer phase change material in building roof for year round thermal management, Energy and Buildings, 40,193-203, 2008.

4. H.J. Alqallaf, E.M Alawadhi, Concrete roof with cylindrical holes containing PCM to reduce the heat gain, Energy and Buildings, 61, 73-80, 2013.

5. E.M Alawadhi, H.J. Alqallaf, Building roof with conical holes containing PCM to reduce the cooling load: Numerical study, Energy Conversion and Management, , 52, 2958-2964, 2011.

6. F. Olivieria, C. Di. Pernab, M. D’Orazioc, L. Olivierid, J. Neila, Experimental measurements and numerical model for the summer performance assessment of extensive green roofs in a Mediterranean coastal climate, Energy and Buildings, 63,1-14, 2013.

7. B. Dvorak, A. Volder, Rooftop temperature reduction from un irrigated modular green roofs in southcentral Texas, Urban Forestry \& Urban Greening, 12, 28- 35, 2013.

8. H. Takebayashi, M. Moriyama, Surface heat budget on green roof and high reflection roof for mitigation of urban heat island, Building and Environment, 42, 2971-2979, 2007.

9. M. Synnefa, Santamouris, H. Akbari, Estimating the effect of using cool coatings on energy loads and thermal comfort in residential buildings in various climatic conditions, Energy and Buildings, 39, 1167-1174, 2007.

10. H. Suehrcke, E.L. Peterson, N. Selby, Effect of roof solar reflectance on the building heat gain in a hot climate, Energy and Buildings, 40, 2224-2235, 2008.

11. A. Pasupathy, L. Athanasius, R. Velraj, R.V. Seeniraj, Experimental investigation and numerical simulation analysis on the thermal performance of a building roof incorporating phase change material (PCM) for thermal management, Applied Thermal Engineering, 28, 556-565, 2008.

12. C. Zhang, Y. Chen, L. Wu, M. Shi, Thermal response of brick wall filled with phase change materials (PCM) under fluctuating outdoor temperatures, Energy and Buildings, 43, 3514-3520, 2011.

13. D. DAvid, F. KuzniK, J.J. Roux, Numerical study of the influence of the convective heat transfer on the dynamical behaviour of a phase change material wall, Applied Thermal Engineering, 31 3117-3124, 2011.

14. P. Ravikumar, D. Prakash, Analysis of thermal comfort in a office room by varying the dimensions of the windows on adjacent walls using CFD: A case study based on numerical simulation, Building simulation: An international journal, 2, 3,187-196, 2009.

15. P. Ravikumar, D. Prakash, Analysis of thermal comfort in a residential room with insect proof screen: A case study by numerical simulation methods, Building simulation: An international journal, 4,3, 217-225, 2011. 